\title{
Protecting silver cultural heritage objects with atomic layer deposited corrosion barriers
}

\author{
Amy E. Marquardt ${ }^{1}$, Eric M. Breitung ${ }^{1,2}$, Terry Drayman-Weisser ${ }^{3}$, Glenn Gates ${ }^{3}$ and R. J. Phaneuf ${ }^{*}$
}

\begin{abstract}
Introduction: Silver, prized throughout history for its luster and shine, develops a black $\mathrm{Ag}_{2} \mathrm{~S}$ tarnish layer that is aesthetically displeasing when exposed to atmospheric pollutants. Tarnishing, and subsequent polishing, leads to irreversible material loss and object damage. Currently, nitrocellulose coatings are often used to prevent silver from tarnishing, however non-uniform coatings and degradation over time limit their effectiveness. Atomic layer deposition (ALD) has been explored as a new method for creating dense, uniform, and conformal coatings on 3-dimensional (3D) objects that are more effective than nitrocellulose in preventing silver from tarnishing.

Results: To create high quality ALD coatings on 3D objects, slowing down the ALD process is critical to ensure proper precursor exposure. Non-ideal deposition of organo-oxy-metallic compounds can occur with fast deposition rates that do not allow sufficient flow around 3D objects. The coatings can be removed by dissolving the $\mathrm{Al}_{2} \mathrm{O}_{3} \mathrm{ALD}$ films in aqueous $\mathrm{NaOH}$. Thicker ALD films prevent defects from occurring on non-ideal surfaces and effectively prevent silver objects from tarnishing under ambient aging conditions.
\end{abstract}

Conclusion: Thick ALD films, deposited with sufficiently long precursor pulse and purge times, may be effective in preventing complex, 3D non-mixed media silver cultural heritage objects from tarnishing.

Keywords: Cultural heritage, Atomic layer deposition, Silver tarnish, Corrosion barrier

\section{Background}

Silver has been a precious and valuable metal dating back nearly 5000 years. Used as both a traded commodity and an artist's material, prized for its luster and shine, silver is plentiful in cultural heritage and private collections. Because of its value and softness, it was rarely used in its pure form (fine silver, $99.9 \%$ silver), instead, silver is commonly alloyed with copper. For example, the sterling standard stipulates a $7.5 \%$ copper concentration. Unlike other precious metals such as gold and platinum, silver is known to tarnish with time forming $\mathrm{Ag}_{2} \mathrm{~S}$ when exposed to low concentrations $(<1 \mathrm{ppb})$ of $\mathrm{H}_{2} \mathrm{~S}$ in ambient environments [1-3]. While $\mathrm{Ag}_{2} \mathrm{~S}$ is the main component in silver tarnish, sulfate, chloride, oxide, and oxygenated

\footnotetext{
*Correspondence: phaneuf@umd.edu

${ }^{1}$ Department of Materials Science and Engineering, University

of Maryland, College Park, MD 20742, USA

Full list of author information is available at the end of the article
}

carbon species can also be present [4]. As the $\mathrm{Ag}_{2} \mathrm{~S}$ tarnish layer increases in thickness, the initially white color will change to yellow at $10 \mathrm{~nm}$, violet at $26 \mathrm{~nm}$, blue at $47 \mathrm{~nm}$, and finally dark gray [5]. Because silver sulfide tarnish is a surface phenomenon, it does not tend to threaten an object's mechanical integrity. It can be, however, aesthetically displeasing and interfere with the readability of surface details.

Tarnish, which often results in undesirable color change, is a damaging process in which copper and silver at the surface are consumed to form sulfide products. Tarnish is commonly removed by polishing silver with an abrasive, although other methods of cleaning silver include chemical, electrolytic, plasma and laser treatments. Polishing, for example, in addition to being a time and labor-intensive process, irreversibly damages the silver object by removing a small amount of metal. Repeated polishing inevitably leads to the loss of 
surface details in the object [6]. Silver plated pieces stand to lose both surface details and the thin layer of surface silver that provides the artist-intended luster and shine. Ideally, silver objects would be preserved in low humidity environments, free of pollutants and corrosive gases, to reduce the need for subsequent polishing. Practically, silver is often stored in controlled environments ideal for mixed collections at $21 \pm 2-3{ }^{\circ} \mathrm{C}$ and $50 \pm 5 \%$ relative humidity $(\mathrm{RH})$ with limited or no filtration of pollutants [7]. It is often not practical to provide the ideal pollutant free and low humidity environment due to cost, space, and accessibility considerations. Because of this coatings are often used to create a physical barrier between the silver object and the environment. Nitrocellulose lacquer is one of the more common barrier films used by conservators to prevent silver objects from tarnishing [8]. Multiple coats of nitrocellulose are often applied by brushing, spraying or dipping the object to ensure complete coverage [9]. The benefits of nitrocellulose lacquers include easy application, improved appearance over other lacquers and a 5-tenfold reduction in required polishing treatment frequency compared to un-coated silver objects $[8,10-12]$.

Despite these benefits, this approach is far from ideal: achieving a uniform film with nitrocellulose is extremely difficult, especially on three-dimensional objects with protrusions such as handles, feet, or lips. Pores or cracks in nitrocellulose coatings are found to occur due to incomplete coverage, causing points of failure and corrosion pitting [13]. Additionally, as nitrocellulose films age, they are known to degrade and yellow from UV exposure, causing an undesirable color change on silver objects and difficult removal after aging $[8,14,15]$.

The limitations of nitrocellulose coatings may potentially be avoided by instead coating silver objects with atomic layer deposited (ALD) metal oxide thin films. ALD diffusion barriers have been successfully used to protect new silver jewelry and silver coins from tarnishing [16]. Conformal, dense metal oxide thin films deposited with ALD on non-mixed media silver and silver alloy art objects meet the cultural heritage conservation requirements of being more effective than current protection methods, reversible without significant substrate alteration, and optically transparent $[17,18]$.

ALD is a thermally activated gas phase process for synthesizing thin solid films by sequentially exposing an object to a series of two or more gaseous reactants, each of which undergoes self-limiting chemisorption surface reactions [19-21]. A sample is placed into the ALD vacuum chamber and heated (experimental details of ALD deposition can be found in the section "Methods"). A metal-organic precursor and oxidizing co-reactant are pulsed into the chamber sequentially, separated by an inert gas purge. A standard ALD cycle for $\mathrm{Al}_{2} \mathrm{O}_{3}$ is schematically shown in Fig. 1. In the top left corner, the metal surface with existing hydroxyl surface groups is exposed to the metal-organic precursor. For the work presented in this report, trimethylaluminum (TMA) is used as the metal-organic precursor and water for the co-reactant. The precursor partially decomposes by reacting with the hydroxyl surface groups, leaving a $-\mathrm{CH}_{3}$ terminated surface. The precursor reacts only with hydroxyl groups and will not react with itself, creating self-limiting growth. Once all hydroxyl sites have been reacted additional exposure to the precursor will not result in additional growth, creating one monolayer of reacted precursor. The system is purged with inert gas to remove excess precursors, reactants or by-products. The $-\mathrm{CH}_{3}$ terminated surface is then exposed to the co-reactant, which in similar self-limiting fashion, reacts on the surface to leave one monolayer of $\mathrm{Al}_{2} \mathrm{O}_{3}$. The hydroxyl-terminated surface is similar to the starting surface, so the ALD process can by cycled to achieve the desired film thickness. The self-limiting nature of the chemistries implemented in ALD process produce high quality, dense and nearly pinhole-free films with thickness control at the atomic level, excellent thickness uniformity and unequalled conformality. ALD has been demonstrated to produce films that are nearly perfectly conformal even for nanoporous substrates whose pore depth to diameter ratio far exceeds ten to one [22-24].

ALD films have been demonstrated to be effective diffusion barriers for corrosion protection [25-29]. The density of $\mathrm{Al}_{2} \mathrm{O}_{3}$ ALD films $\left(3.0-2.5 \mathrm{~g} / \mathrm{cm}^{3}\right.$, depending on deposition temperature) is at least 1.5 times greater than the density of nitrocellulose $\left(1.6 \mathrm{~g} / \mathrm{cm}^{3}\right.$, depending on the nitrogen content), creating better barriers that slow the rate of gas diffusion [30,31]. For applications in cultural heritage, the thickness of a barrier film involves a tradeoff; a thick barrier film results in a long diffusion path for corrosive gases, while thicker films tend to more profoundly affect the optical properties and visual appearance of the film. The visual appearance of the ALD films can be tuned by varying the thickness and refractive index of the ALD film structures used on a substrate [32]. Single or multilayer ALD films consisting of multiple materials or film thicknesses can be deposited with sub-nanometer control over the coating thickness. Optical modeling techniques, adopted from high precision optical coatings for devices like telescopes and spectrometers, can be used to predict, optimize, and minimize surface coloration [33,34]. This flexibility allows for the creation of nearly invisible ALD films on both coated silver and sterling silver substrates [18].

Nearly perfect conformality with ALD is achievable even for substrate feature aspect ratios far exceeding 


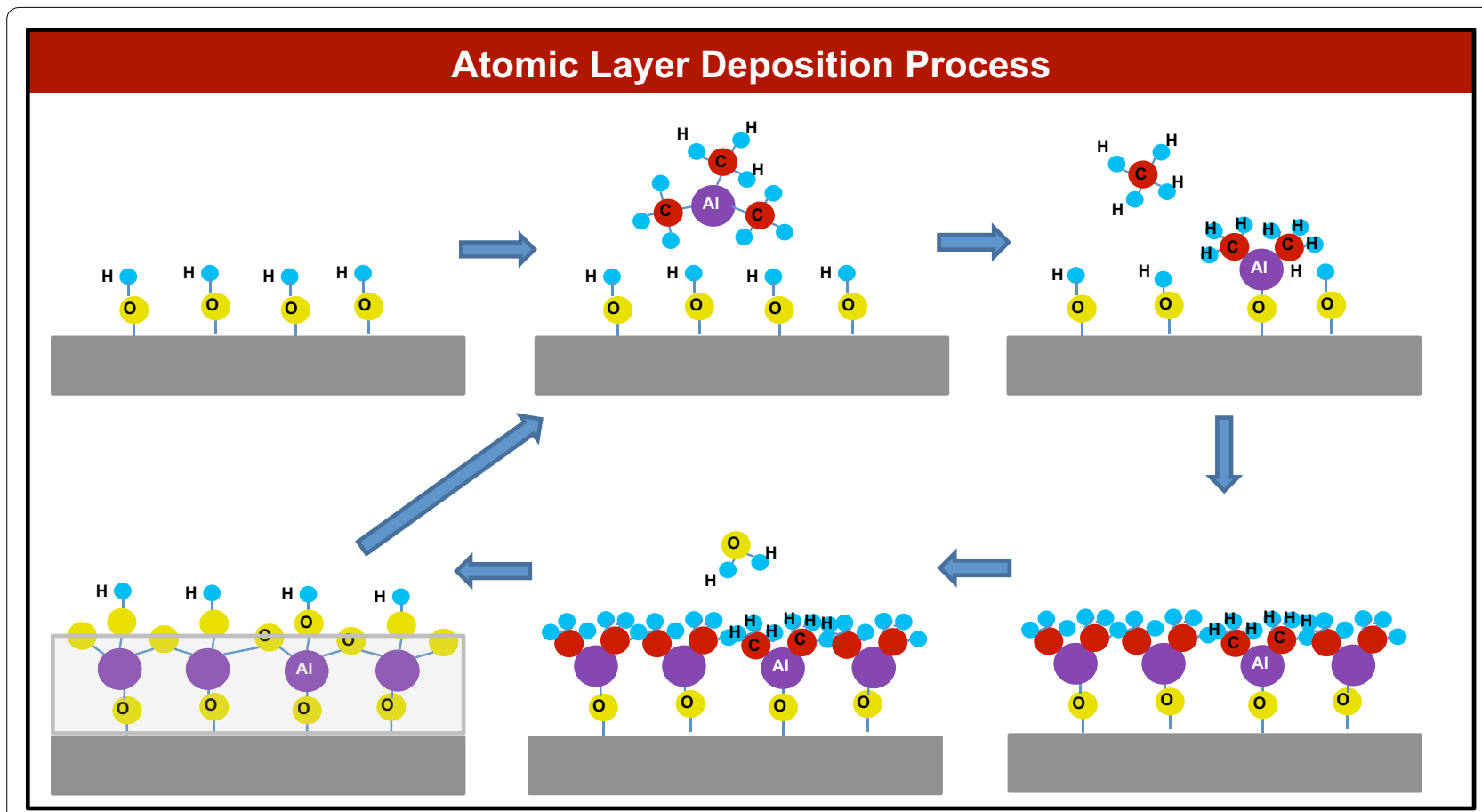

Fig. 1 ALD process: schematic of one cycle of $\mathrm{Al}_{2} \mathrm{O}_{3} \mathrm{ALD}$ growth. The hydroxyl-terminated starting surface is exposed to a metal-organic precursor that reacts with the surface in a self-limiting reaction. Once the system is purged with an inert gas to remove excess precursors and by-products, a second co-reactant is introduced and reacts to form one monolayer of $\mathrm{Al}_{2} \mathrm{O}_{3} \mathrm{ALD}$. The ending hydroxyl-terminated surface is similar to the starting surface, allowing the process to be cycled to grow the desired film thickness

those typically found on cultural heritage objects. As a result, ALD can create uniform coatings on intricately detailed surfaces with inscriptions and surface texturing. Coating 3-dimensional (3D) objects with ALD is possible, as it is a 'non-directional' technique, where unlike a directional technique, such as spray coating, the location of the source of the ALD precursor chemicals relative to the object does not affect deposition uniformity. Rather, as long as the ALD precursors are allowed sufficient time to surround and bind to the object, reaching all crevices, a conformal coating can be achieved. Indeed, due to the non-directional nature of the ALD process, any surface within the reactor can, in principle, be coated, allowing the process to be scaled up to treat large objects or simultaneously coat multiple objects, the limiting factor being only the size of the ALD coating chamber. Large volume ALD reactors are commercially available though modifications to the technology may be required for cultural heritage applications.

Additional challenges arise due to the complexity of many cultural heritage objects. ALD films are limited to use on silver and silver alloy objects as current alkaline solutions used for ALD coating removal are not recommended for use on mixed media objects or objects with microcracks or pores. ALD films thicknesses may need to be tailored to minimize appearance changes on objects with changing alloy compositions or the presence of solder or gilding. Additionally, the elevated temperatures, $100-150{ }^{\circ} \mathrm{C}$, used to apply the ALD films in this study may cause microstructure changes to silver alloys. The vacuum level used for deposition, 3-5 mbar, may not be suitable for cultural heritage objects. However, ALD systems for atmospheric pressure, low temperature processing have been developed [30, 35, 36], and would likely be more suitable for cultural heritage objects.

Our recent work demonstrates that ALD films are a promising technique to prevent damage from the corrosion process, and subsequent polishing, for silver cultural heritage objects. Our previous results find that $20 \mathrm{~nm}$ $\mathrm{Al}_{2} \mathrm{O}_{3}$ ALD films protect silver from tarnishing nearly 15 times longer than microns-thick nitrocellulose films: this amounts to a potential ambient effective film lifetime of 150 years. We note, however, that this may represent an upper limit of ALD effective lifetimes-in our earlier work coatings were applied to flat, clean, 2-dimensional ideal silver substrates [16-18]. In the work presented here we investigate the effectiveness of ALD coatings on nonideal, 3D historic objects. As we show below, additional challenges arise in creating quality ALD coatings on realistic art objects. Extended precursor pulse/purge times 
are required to adequately coat complex $3 \mathrm{D}$ geometries. Adjusting the concentration of aqueous $\mathrm{NaOH}$ solutions allows for complete removal of the ALD. In addition, we find that thicker ALD films are needed to reduce pinhole defects in ALD films on non-ideal substrates.

\section{Results}

\section{Coating 3-dimensional silver objects}

In the results presented in this section, we test the ability of ALD films to coat realistic 3D art objects, using a set of historic cast and surface chased sterling silver knives from a personal collection as an example. The knives were polished and ultrasonically cleaned in a series of solvents prior to deposition of 10 and $100 \mathrm{~nm}$ thick $\mathrm{Al}_{2} \mathrm{O}_{3}$ ALD films at $100{ }^{\circ} \mathrm{C}$. A schematic of the chamber is shown in Fig. 2a. An important issue is how to maintain adequate flow around mechanical supports that are required for complete coating of all object surfaces. The knives were supported by two points of contact, one at the handle in a high point in the decorative details and the other at the blade tip where it rested on the ALD chamber floor, Fig. 2b. To mitigate restricted flow issues the knives were flipped half way through each ALD process, the stamped side of the knife blade always faced the ALD chamber floor during the first deposition (Side B) and facing the ALD chamber lid during the second, Fig. 2b. Trimethylaluminum (TMA) and water were used to deposit $\mathrm{Al}_{2} \mathrm{O}_{3}$ ALD films. The precursors were alternately pulsed into the ALD chamber one at a time, with a nitrogen purge in between precursors to evacuate the chamber. The precursor pulse and nitrogen purge times during deposition were varied at constant flow rates to determine the minimum values for achieving uniform ALD coatings. The precursor pulse times were varied from 0.5 to $2 \mathrm{~s}$ and the nitrogen purge times were varied from 1 to $4 \mathrm{~s}$. The lower limit in each case corresponds to the amount of time required to deliver sufficient precursor to the silver surface, and sufficient nitrogen to purge unreacted precursor, to produce uniform ALD coatings on flat substrates. Appropriate precursor pulse times are dependent on the ALD chamber dimensions and must be determined for each ALD chamber. Figure 3 shows photographic images of: (a) a bare knife with no coating (top),

a

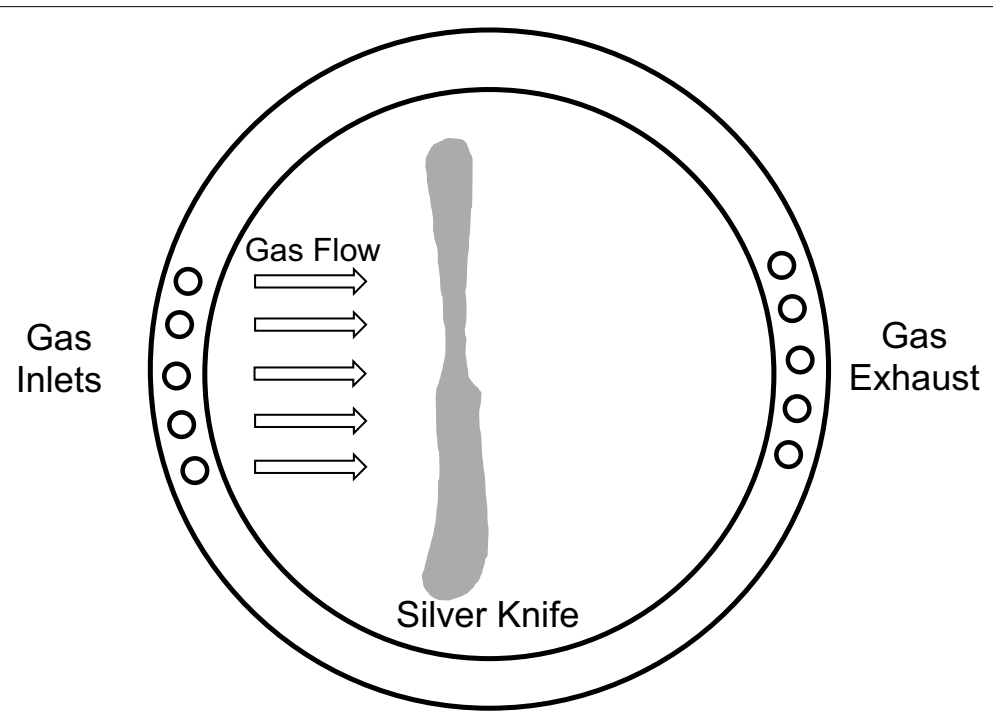

b

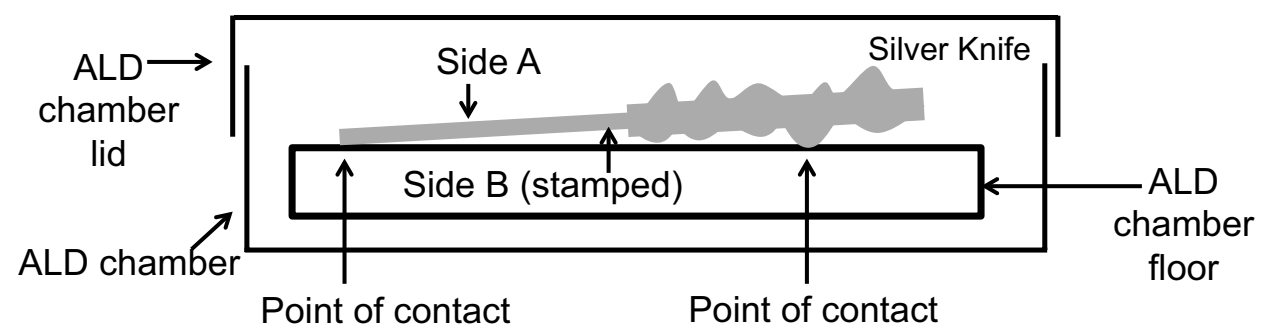

Fig. 2 Schematic of ALD chamber: a the precursors and $\mathrm{N}_{2}$ gas are pulsed in through the gas inlets and exit through the exhaust, making the gas flow from left to right over the silver knife. $\mathbf{b}$ The knife made two points of contact with the ALD chamber floor, one on the blade and the other at a high point on the handle. Side A is defined as side of the knife that faced the ALD chamber lid during the first half of deposition, Side B is defined as the stamped knife side that faced the chamber floor during the first half of deposition 


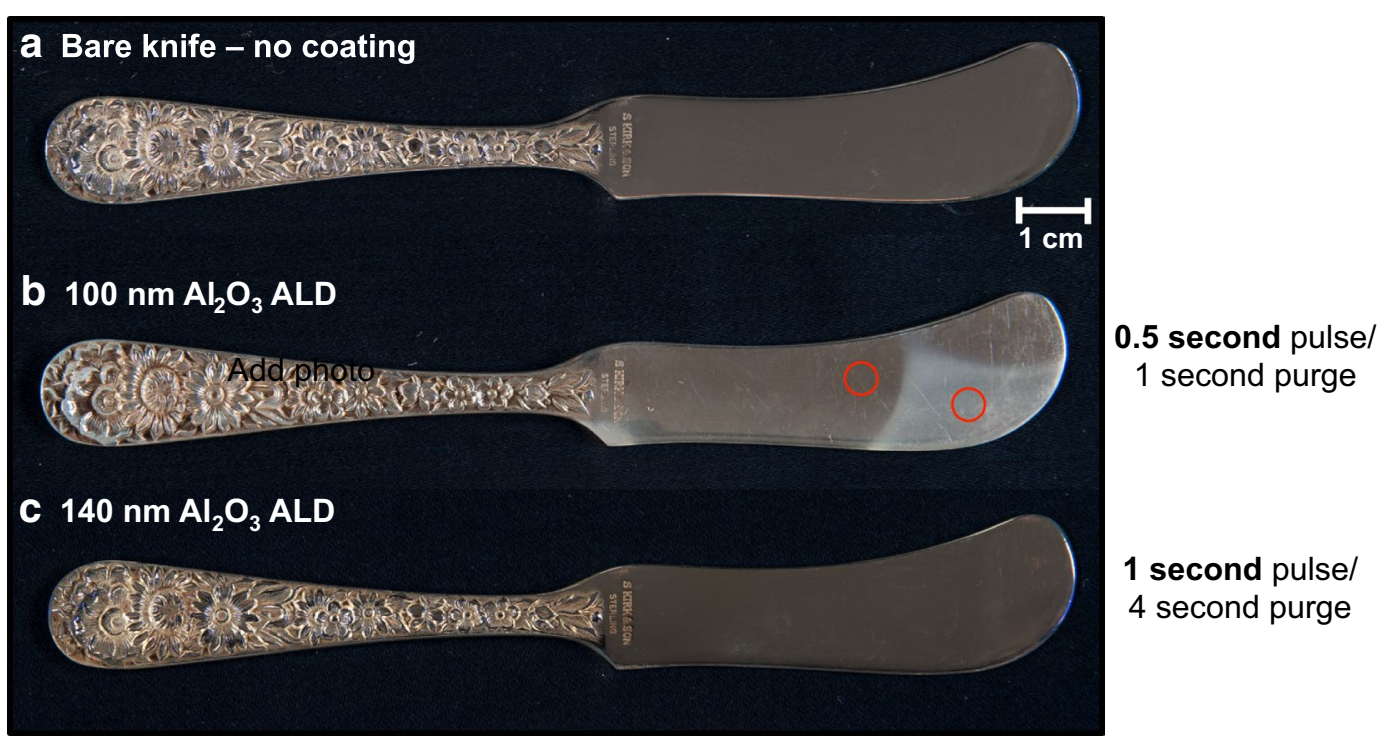

Fig. 3 ALD coatings on silver knives: silver knives a bare, without an ALD coating, b with a $100 \mathrm{~nm} \mathrm{Al}_{2} \mathrm{O}_{3} \mathrm{ALD}_{\mathrm{L}}$ coating deposited with a $0.5 \mathrm{~s}$ TMA pulse/1 $\mathrm{s} \mathrm{N}_{2}$ purge (fast deposition), and c $140 \mathrm{~nm} \mathrm{Al} \mathrm{O}_{3}$ ALD coating deposited with a $1 \mathrm{~s}$ TMA pulse/4 s $\mathrm{N}_{2}$ purge (slow deposition). Hazy areas corresponding to incomplete ALD reactions, can be reduced by slowing down the deposition speed, allowing sufficient time for precursor diffusion around 3-dimensional objects. Side B (facing ALD chamber floor during first half of deposition) is shown for all knives pictured in this image. Areas of AFM analysis, shown in Fig. 4, and EDS analysis, shown in Table 1, are circled in $\mathbf{b}$

(b) a knife coated with $100 \mathrm{~nm}$ of $\mathrm{Al}_{2} \mathrm{O}_{3}$ ALD using a $0.5 \mathrm{~s}$ pulse and a $1 \mathrm{~s}$ purge (middle) and (c) a knife coated with $140 \mathrm{~nm} \mathrm{Al}_{2} \mathrm{O}_{3} \mathrm{ALD}$ using a $1 \mathrm{~s}$ pulse and a $4 \mathrm{~s}$ purge (bottom). Hazy regions, areas where the film appeared white and nearly opaque, for example, near the tip of the knife (as indicated by the right circle in Fig. 3b), were observed on the knife coated with the shorter of $0.5 \mathrm{~s}$ pulse/ $1 \mathrm{~s}$ purge times (Fig. 3b). Both sides of this knife blade exhibited haze, with a large hazy region on Side B, which faced the chamber floor during the first half of the ALD film process. The opposite side of the knives (Side A) looked similar to Side B for the knives shown in Fig. 3a, c and are not pictured, while the knife in Fig. 3b exhibited fewer hazy regions on its Side A and is also not shown. Scanning electron microscopy (SEM) and energy dispersive spectroscopic (EDS) analysis were conducted in the circled areas in Fig. $3 \mathrm{~b}$ and showed that both the hazy and clear regions of the knife contained aluminum, as summarized in leftmost columns of Table 1 . This indicates that an $\mathrm{Al}_{2} \mathrm{O}_{3}$ coating had deposited across the entire knife.

The nature of the hazy regions observed on the knife coated with shorter pulse/purge times seen in Fig. 3b were further investigated using atomic force microscopy (AFM). Images of the hazy areas on the knife were collected in the circled areas in Fig. 3b and showed a high density of small particles covering the surface, shown in Fig. 4b. In comparison, AFM analysis of the clear areas of the knife (left circle in Fig. 3b), as seen in Fig. 4a, indicates a much smaller density of such particles on the surface. The RMS roughness determined from the hazy area is $50.7 \pm 4.9 \mathrm{~nm}$, or roughly twice that from the clear area, where we measured a value of $24.0 \pm 3.9 \mathrm{~nm}$. Typically, minimal changes to the RMS roughness are observed after applying $\mathrm{ALD} \mathrm{Al}_{2} \mathrm{O}_{3}$ films [33]; indeed this type of coating produces extreme conformality [23, 24]. As an uncoated sterling silver had a RMS roughness of $19.5 \pm 2.4 \mathrm{~nm}$ and after a $100 \mathrm{~nm}$ thick $\mathrm{Al}_{2} \mathrm{O}_{3}$ ALD film was applied, the RMS roughness was not significantly changed at $18.7 \pm 0.8 \mathrm{~nm}$. We conclude that diffuse scattering of light due to the presence of particles at the surface is causing the hazy appearance.

Raman spectroscopy analysis was also performed at clear and hazy regions of the knife, which are circled in Fig. $3 \mathrm{~b}$ and the results presented in Fig. 4c. In both the hazy and clear regions peaks at 1355, 1594 and $2919 \mathrm{~cm}^{-1}$ were identified. The 1594 and $1355 \mathrm{~cm}^{-1}$ signals are near frequencies attributed to ring stretching in polyaromatic compounds, or disordered graphitic carbon species, at 1580 and $1360 \mathrm{~cm}^{-1}$. These are generally referred to as the $G$ band and $D$ band, respectively [37-39]. The ratio of the $G$ and $D$ band intensities $\left(I_{D}\right.$ and $I_{G}$ ) is a measure of the graphitization level, as the $\mathrm{G}$ band alone is present in highly ordered graphite while the D band appears, and increases in intensity with increasing disorder [39, 40]. The $\mathrm{I}_{\mathrm{D}} / \mathrm{I}_{\mathrm{G}}$ ratios for the hazy and clear regions of the knife are 0.97 and 0.98 , respectively, indicating a relatively low 
Table 1 EDS analysis of ALD coating removal

\begin{tabular}{|c|c|c|c|c|c|c|c|}
\hline & \multicolumn{2}{|l|}{$100 \mathrm{~nm} \mathrm{Al}_{2} \mathrm{O}_{3} \mathrm{ALD}$} & \multirow{2}{*}{$\begin{array}{l}140 \mathrm{~nm} \mathrm{Al} \mathrm{O}_{3} \text { ALD } \\
\text { Clear area (At \%) }\end{array}$} & \multicolumn{2}{|c|}{0.05 wt $\% \mathrm{NaOH}$ for $2 \mathrm{~h}$} & \multicolumn{2}{|c|}{$0.5 \mathrm{wt} \% \mathrm{NaOH}$ for $25 \mathrm{~min}$} \\
\hline & Clear area (At \%) & Hazy area (At \%) & & Clear area (At \%) & Hazy area (At \%) & Clear area (At \%) & Hazy area (At \%) \\
\hline $\mathrm{Ag}$ & $34.27 \pm 2.4$ & $40.47 \pm 2.5$ & $4.64 \pm 1.1$ & $53.85 \pm 2.6$ & $47.16 \pm 2.6$ & $88.12 \pm 2.7$ & $88.36 \pm 2.8$ \\
\hline $\mathrm{Cu}$ & $3.50 \pm 0.3$ & $6.12 \pm 0.4$ & - & $8.34 \pm 0.5$ & $7.23 \pm 0.5$ & $11.88 \pm 0.5$ & $11.64 \pm 0.5$ \\
\hline $\mathrm{Al}$ & $5.70 \pm 0.2$ & $4.77 \pm 0.2$ & $17.47 \pm 0.8$ & $2.54 \pm 0.1$ & $3.67 \pm 0.2$ & - & - \\
\hline $\mathrm{O}$ & $56.53 \pm 3.4$ & $48.65 \pm 3.2$ & $77.89 \pm 5.0$ & $35.27 \pm 2.3$ & $41.96 \pm 2.8$ & - & - \\
\hline
\end{tabular}

EDS analysis of $\mathrm{Ag}, \mathrm{Cu}, \mathrm{Al}$ and $\mathrm{O}$ in the clear and hazy ALD coating areas are shown for both concentrations of $\mathrm{NaOH}$

ALD coating removal was incomplete after removal with $0.05 \mathrm{wt} \% \mathrm{NaOH}$, as indicated by the presence of $\mathrm{Al}$ and $\mathrm{O}$

Complete coating removal was achieved with $0.5 \mathrm{wt} \% \mathrm{NaOH}$

degree of graphitization. Further, the intensity of both the $G$ and $D$ bands is much higher in the hazy region of the knife. Taken together, these observations indicate a higher abundance of a disordered $\mathrm{C}-\mathrm{H}$ species in the visibly hazy regions. Additionally, the region from 2700 to $3000 \mathrm{~cm}^{-1}$ in Raman spectra is generally attributed to the $\mathrm{C}-\mathrm{H}$ stretching mode in alkyl hydrocarbons [37, 39 ]. Both the clear and hazy regions of the knife contain a peak at $2919 \mathrm{~cm}^{-1}$, however, the intensity is significantly higher in the hazy region.

We next consider the significance of the Raman analysis. Trimethylaluminum (TMA) and water were the two precursors used to deposit the $\mathrm{Al}_{2} \mathrm{O}_{3}$ ALD films. TMA $\left(\mathrm{Al}_{2}\left(\mathrm{CH}_{3}\right)_{6}\right.$ is composed of a central aluminum atom surrounded by three methyl groups $\left(-\mathrm{CH}_{3}\right)$. The intense Raman signal of alkyl groups in the hazy region suggests an incomplete ALD reaction, in which the methyl ligands in the chemisorbed species from the TMA sub-reaction were not fully replaced during the subsequent $\mathrm{H}_{2} \mathrm{O}$ precursor sub-reaction. We conclude that a pure $\mathrm{Al}_{2} \mathrm{O}_{3}$ film was likely not deposited in the hazy regions, but instead a mixture of $\mathrm{Al}_{2} \mathrm{O}_{3}$ and $\mathrm{Al}_{\mathrm{x}} \mathrm{O}_{\mathrm{y}}\left(\mathrm{CH}_{3}\right)_{\mathrm{z}}$ organo-oxy-metallic compounds is likely present. It is likely that both precursors, TMA and water, had insufficient precursor flow through this region and prevented the complete replacement of each methyl group with a hydroxyl group $(-\mathrm{OH})$, which is required for dense and uniform, layer-by-layer $\mathrm{Al}_{2} \mathrm{O}_{3}$ ALD growth.

Our results show that increasing the precursor pulse and purge times is an effective way to suppress the formation of hazy regions in the ALD coatings. The knife coated with $140 \mathrm{~nm} \mathrm{Al}_{2} \mathrm{O}_{3}$ ALD film (Fig. 3c), where a $1 \mathrm{~s}$ TMA pulse and $4 \mathrm{~s}$ nitrogen purge (bottom) was used, showed no visible hazy regions in the coating (note that the colored areas at the tip of the knives are artifacts of edge diffraction, which produces dispersion according to wavelength, along with the chromatic aberration of the lens used in making the image; these are present even in the absence of a coating, as seen in Fig. 3a). EDS analysis, shown in the second column of Table 1 , revealed the presence of aluminum across the surface of the knife, indicating complete coverage by the $\mathrm{Al}_{2} \mathrm{O}_{3}$ ALD film. Our results indicate that longer pulse and purge times are required for complex 3D objects, particularly near supports, to allow the precursors and by-products adequate time to diffuse to all portions of the object. Understanding the precursor reaction and transport, tortuous diffusion paths and ALD chamber flow dynamics around complex objects is critical and an area of ongoing study [41-43]. While this topic is beyond the scope of this paper, we note that the apex of the prominent hazy plume in Fig. 3b coincides with the position of one of the supports that was used to hold the knife in place.

\section{ALD coating removal}

Removal of the ALD coating without significant alterations to the underlying substrate must be demonstrated to meet one of the requirements in cultural heritage conservation. Previously, we have shown that aqueous $\mathrm{NaOH}$ solutions as weak as $0.05 \%$ (pH 11) can be used to effectively remove $\mathrm{Al}_{2} \mathrm{O}_{3} \mathrm{ALD}$ films with no significant change to flat sterling silver substrates. However, the reversibility of hazy coatings, such as those shown in Fig. 4b, was not addressed. To be discussed here is whether the organooxy-metallic residues in the films might affect reversibility and if these residues found in the hazy areas are as easily removed as the clear areas. To address this, the knife shown in Fig. 3b was immersed in 0.05 wt\% aqueous $\mathrm{NaOH}$ for $2 \mathrm{~h}$ to remove $100 \mathrm{~nm} \mathrm{Al}_{2} \mathrm{O}_{3}$ ALD, which is $37 \mathrm{~min}$ more than the time required to remove $100 \mathrm{~nm}$ of a typical amorphous ALD alumina (clear area). EDS analysis, however, showed the coating remained both 


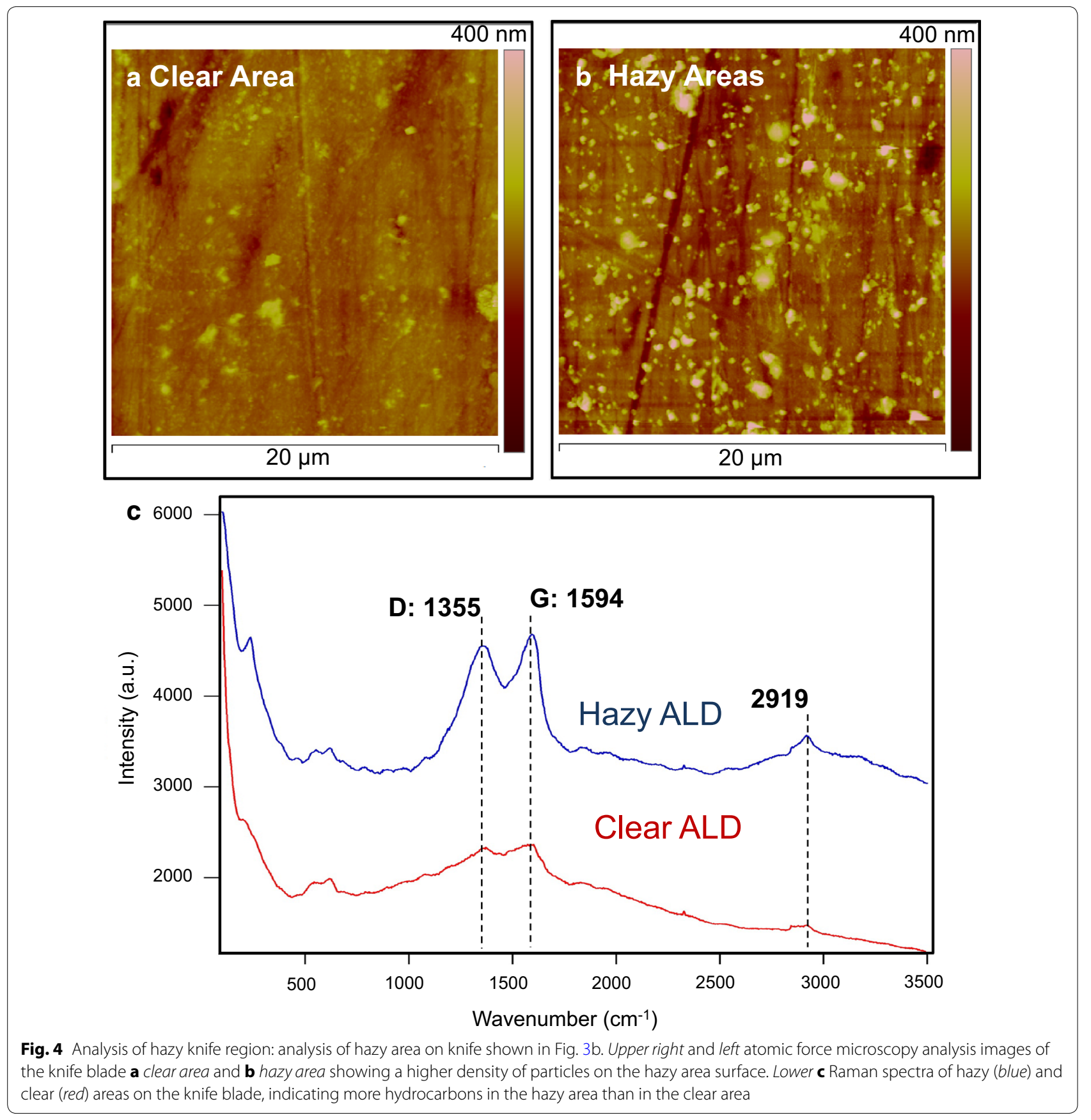

in the clear and hazy regions, as shown in Table 1 . The concentration of $\mathrm{NaOH}$ was increased to $0.5 \mathrm{wt} \%$ (pH 11) for $25 \mathrm{~min}$ in a second attempt to remove the ALD coating. EDS analysis confirmed the complete removal of the ALD coating with higher concentrations of $\mathrm{NaOH}$ in both the hazy and clear areas of the coating, also shown in Table 1. Seemingly the residual organo-oxy-metallic residues have a passivating effect, which is overcome by the higher $\mathrm{NaOH}$ concentration.

\section{Overcoming pinholes in ALD films}

Contiguous ALD films have been proven to be effective diffusion barriers for preventing corrosive gases in the environment from reacting with the substrate [25-29]. Recent results show that such films can be effective in reducing the rate of silver tarnish formation by preventing atmospheric $\mathrm{H}_{2} \mathrm{~S}$ gas from reaching and reacting with the silver surface [16]. The effectiveness of such an approach for protecting art objects, however, can be 
limited by holes or point defects, which reduce the effective film lifetime at the defects. Holes in the barrier coating act as fast paths for corrosive gas diffusion to the underlying metal, resulting in more rapid tarnish rates than in the coated areas. Once tarnishing occurs at such defects, the entire coating must be replaced and the tarnish spot removed through mechanical polishing. While ALD films have been reported to be nearly defect free coatings, pinholes can occasionally occur $[44,45]$.

Thin, $10 \mathrm{~nm} \mathrm{Al}_{2} \mathrm{O}_{3}$ ALD films can avoid visible appearance changes due to thin film interference effects; however, they can also contain defects in the ALD coating. Because identifying pinholes, should they exist, in thicker films has proven extremely difficult, $10 \mathrm{~nm}$ films were applied to investigate the nature of pinholes in $\mathrm{Al}_{2} \mathrm{O}_{3}$ ALD films. Figure 5a shows photographic evidence of an ALD pinhole defect on a silver knife coated with $10 \mathrm{~nm}$ $\mathrm{Al}_{2} \mathrm{O}_{3}$ ALD that was subsequently aged indoors under ambient laboratory conditions with no pollutant filtration for 1 year. The temperature and humidity varied from 65 to $75^{\circ} \mathrm{F}\left(18\right.$ to $24^{\circ} \mathrm{C}$ ) and 30 to $70 \%$ relative humidity. A visual inspection of the knife revealed a single tarnish spot on the blade, approximately $1 \mathrm{~mm}$ in diameter. SEM images of the area showed a large circular contrasted area with a smaller, approximately $50 \mu \mathrm{m}$, more heavily contrasted area near the center, as seen in Fig. 5b. To correlate the image contrast with stoichiometry we carried out X-ray photoelectron spectroscopy (XPS) at a number of positions across the tarnish spot. The gray scale image in Fig. $5 c$ shows the intensity map of the adjusted $C 1$ s core level signal. The dark area at the top of the gray scale image is due to the curvature of the knife blade, causing the knife surface to be out of focus with the XPS detector. Overlaid on this gray scale image are the profiles of the $\mathrm{O} 1 \mathrm{~s}, \mathrm{Al} 2 \mathrm{p}, \mathrm{S} \mathrm{2p}$ and $\mathrm{Ag} 3 \mathrm{~d}$ core levels intensities from spectra taken at different points across the image. The result is an effective concentration profile for each of the elements across the tarnish spot center. The $\mathrm{O}$ ls and $\mathrm{Al}$ $2 \mathrm{p}$ line profiles show minima at the center of the tarnish spot, coinciding with maxima in the S 2 p and Ag 3d signals. We conclude that the center spot in the SEM image likely corresponds to a defect in the $\mathrm{Al}_{2} \mathrm{O}_{3}$ ALD coating that left a portion of the silver knife uncoated and vulnerable to tarnishing, and that this tarnish region subsequently grew laterally, under the ALD oxide film. The cause of the pinhole is unknown; we speculate that it may have originated from the presence of a dust particle, which shadowed the surface during deposition [45].

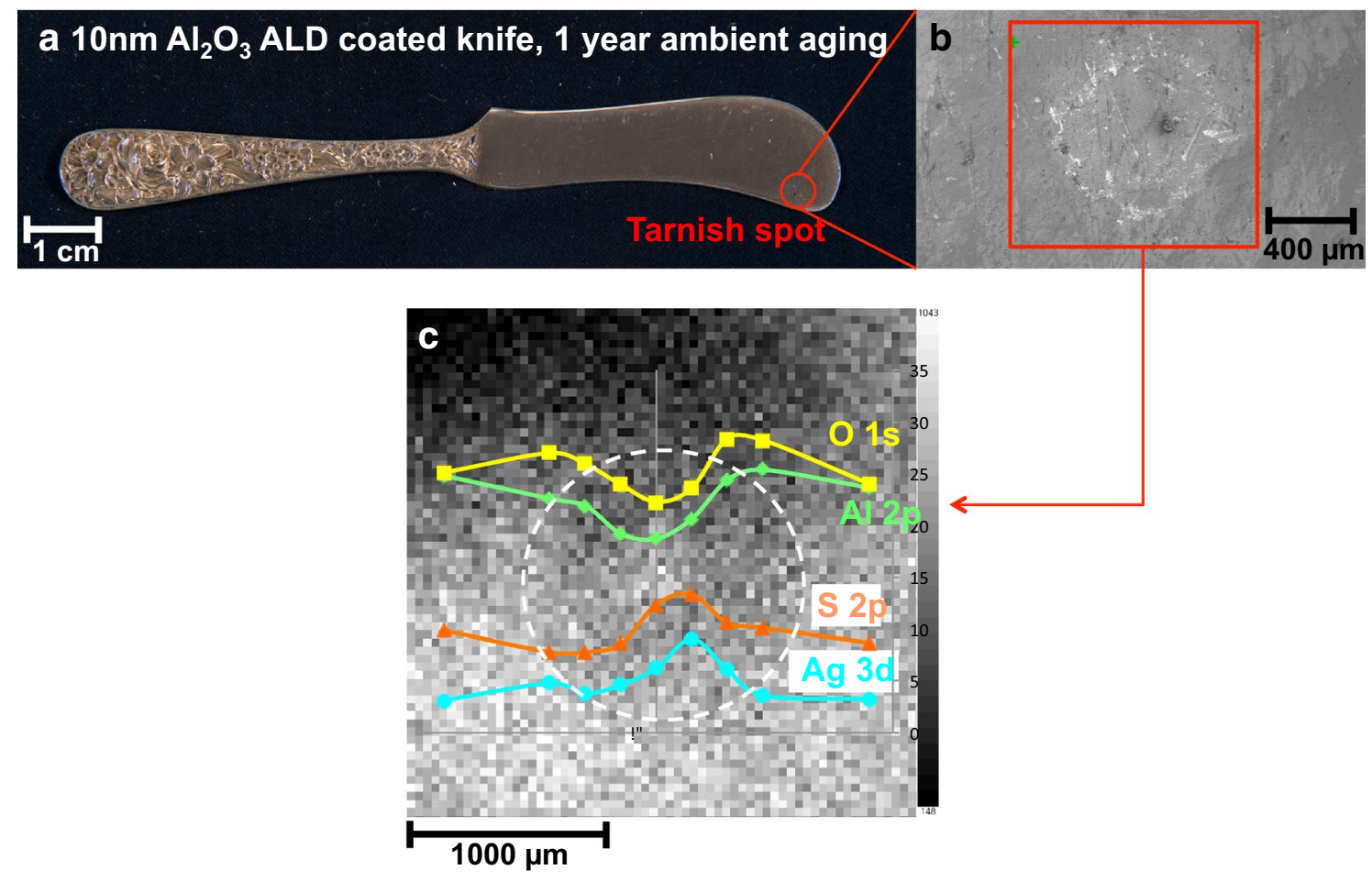

Fig. 5 XPS imaging of knife tarnish spot: Analysis of a tarnish spot visible on $10 \mathrm{~nm} \mathrm{Al} \mathrm{O}_{3}$ ALD coated silver knife blade after 1 year ambient aging with (b) SEM image and $\mathbf{c}$ XPS imaging with overlain quantified line profile of O 1s, Al 2p, S 2p and Ag 3d spectra. The tarnish spot corresponds to a defect or hole in the $\mathrm{Al}_{2} \mathrm{O}_{3}$ ALD coating. Knife Side A shown in this image 
We find evidence that increasing the ALD film thickness is an effective strategy to minimize pinhole defects, despite residues that may be present on the surface. Similar knives coated with much thicker, 100 and $140 \mathrm{~nm}$ $\mathrm{Al}_{2} \mathrm{O}_{3}$ ALD films were aged under the similar indoor ambient conditions for 1 year, but neither knife showed signs of tarnish or film defects. Both knives were inspected visually and with a light microscope to detect tarnish but no dark spots were identified. The $100 \mathrm{~nm}$ ALD film after aging is shown in Fig. 6. We note that the 10 and $100 \mathrm{~nm}$ $\mathrm{Al}_{2} \mathrm{O}_{3}$ ALD-coated knives were cleaned and coated at the same time while the $140 \mathrm{~nm} \mathrm{Al}_{2} \mathrm{O}_{3}$ ALD was coated 1 year later. All knives were exposed to similar levels of polishing residue and dust conditions; yet the thicker 100 and $140 \mathrm{~nm} \mathrm{Al} \mathrm{O}_{3}$ ALD coatings seemingly covered any pinhole defects. Our results suggest that increasing ALD film thickness might effectively cover film defects that form during the initial stages of film growth.

Further evidence that thicker ALD films more effectively cover silver surfaces was observed in ALD film porosity measurements. Using electrochemical impedance spectroscopy (EIS) we measured the ALD film porosity for a series of $\mathrm{Al}_{2} \mathrm{O}_{3}$ ALD films 5, 0, 20, 70, and $100 \mathrm{~nm}$ in thickness, deposited on thermally evaporated silver substrates. A Bode plot summary of the electrochemical spectra results for the uncoated sample, and ALD coated silver samples, is shown in Fig. 7a. The magnitude of the low frequency impedance limit (effectively the resistance of the equivalent circuit) increases dramatically with increasing ALD film thickness, consistent with decreasing exposed area fraction. A measure of the porosity, specifically the ratio of the uncoated polarization resistance to the ALD coated polarization resistance (Eq. 1, described in the section "Methods"), of the ALD films was calculated from the low frequency intercept with the real impedance axis, and is plotted in Fig. 7b. The porosity of the ALD films decreases strongly as the film thickness increases from 0 to $100 \mathrm{~nm}$. We find that ALD $\mathrm{Al}_{2} \mathrm{O}_{3}$ films under $10 \mathrm{~nm}$ in thickness have a significant density of pinhole defects, indicating the initial growth of the ALD film is defective. As the coating thickness is increased, these holes or defects apparently tend to fill in or become covered with the additional alumina deposition.

The samples used for the EIS measurements shown in Fig. 7 were relatively clean, flat silver surfaces with little chemical heterogeneity, providing a nearly ideal silver substrate for ALD; thus these results likely set a lower limit on ALD coating porosity to be expected on art objects, such as the sterling silver knives discussed above. The porosity of the $10 \mathrm{~nm} \mathrm{Al} \mathrm{O}_{3}$ ALD film on the knives is likely greater than the same coating on an ideal silver substrates. The silver knife surface is likely more chemically heterogeneous due to the $\mathrm{Ag}-\mathrm{Cu}$ alloy composition and likely has existing oxides or residues present from handling and previous treatments. This speculation is supported by our previous reported results showing that the porosity of thin $10 \mathrm{~nm} \mathrm{Al}_{2} \mathrm{O}_{3}$ ALD films depended on the prior treatment of the silver surface, while $100 \mathrm{~nm}$ thick $\mathrm{Al}_{2} \mathrm{O}_{3}$ ALD films had low porosity that was nearly independent of the surface treatment [18]. For art objects, we expect that thicker ALD coatings will be required to prevent surface heterogeneities, residues or particles from causing defects in the ALD coating.

\section{Methods}

\section{Sample preparation}

Cast and surface chased sterling silver butter knives from a personal collection were used to test the application of ALD films on 3D objects. The knives were polished using a slurry of ethanol and $0.04 \mu \mathrm{m}$ precipitated chalk $\left(\mathrm{CaCO}_{3}\right)$ followed by a quick polishing with a silver cleaning cloth (Goddard's Long Shine ${ }^{\circledR}$ ) to remove tarnish. Before ALD films were applied, the knives were cleaned by immersion in ultrasonic baths of (all reagent grade) trichloroethylene, acetone, methanol and isopropanol, followed by a deionized water rinse and blow drying with $\mathrm{N}_{2}$ gas.

Silver thin films for electrochemical impedance spectroscopy were deposited on $\mathrm{Si}$ wafers using the Metra

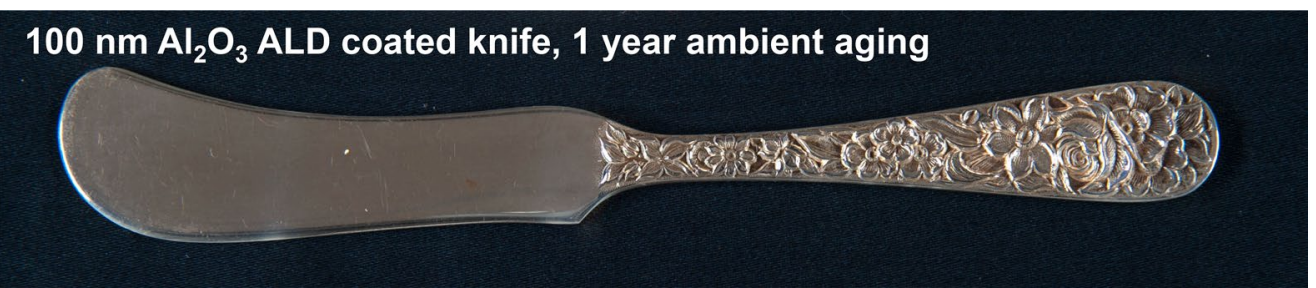

Fig. 6 Thick, protective ALD coating on knife: silver knife coated with $100 \mathrm{~nm} \mathrm{Al} \mathrm{O}_{3}$ ALD after 1 year indoor aging at the same ambient conditions as the knife shown in Fig. 5a. No tarnish spots were visible on the $100 \mathrm{~nm}$ coated knife, indicating a thicker ALD coating effectively coats any defects that may be present in early growth stages of ALD films. Knife Side A shown in this image 

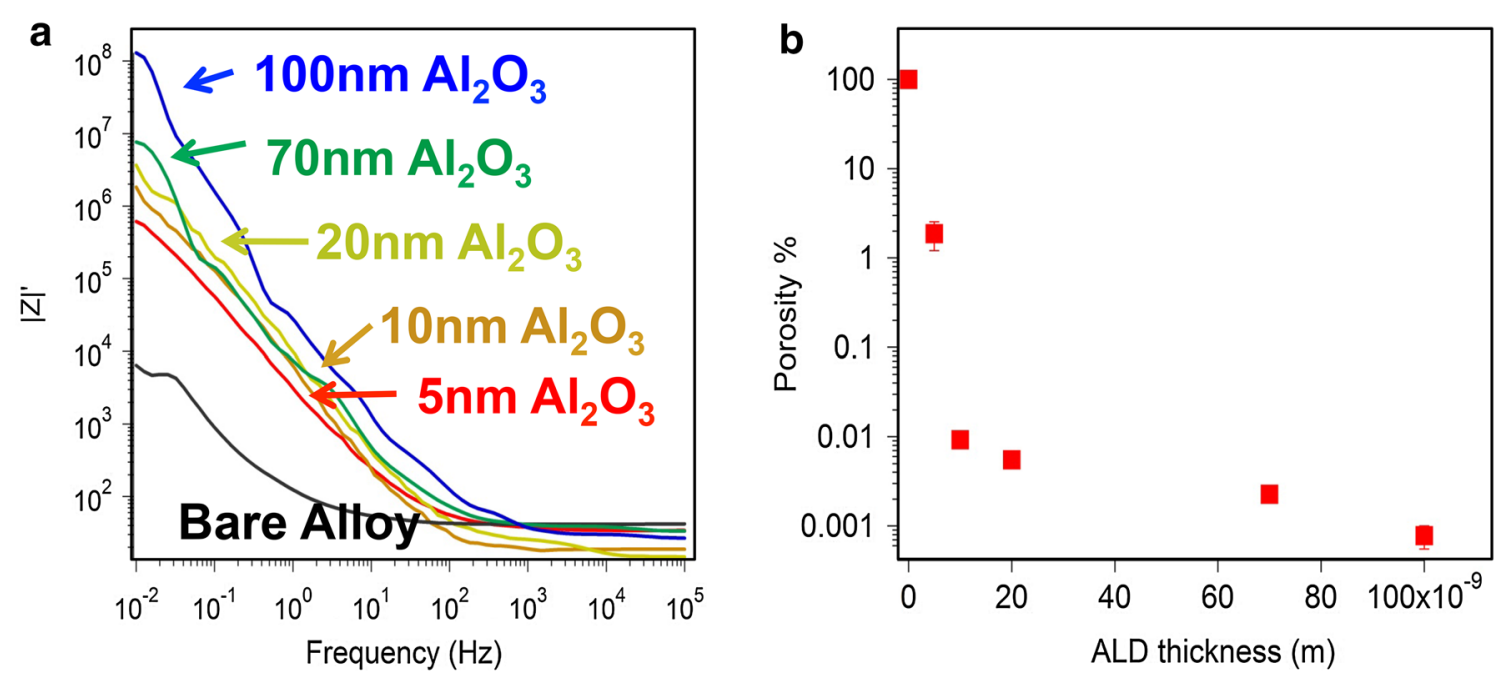

Fig. 7 Porosity of ALD films: electrochemical impedance spectroscopy of 5, 10, 20, 70 and $100 \mathrm{~nm} \mathrm{Al}_{2} \mathrm{O}_{3} \mathrm{ALD}_{\mathrm{L}}$ coated silver substrates with the a electrochemical spectra (Bode plot) and b calculated porosity (Eq. 1)

Thermal Evaporator. A $10 \mathrm{~nm} \mathrm{Al}_{2} \mathrm{O}_{3} \mathrm{ALD}$ adhesion layer was deposited on the Si wafers before Ag deposition to prevent the Ag delaminating from the Si wafer. $99.999 \%$ Ag (Sigma-Aldrich) was deposited at a rate of $\sim 10 \AA / \mathrm{s}$ under a base pressure of $2.0 \times 10^{6}$ Torr.

\section{Atomic layer deposited $\mathrm{Al}_{2} \mathrm{O}_{3}$}

A Beneq TFS 500 atomic layer deposition (ALD) system with a $200 \times 170 \times 25 \mathrm{~mm}$ sub-chamber produced all $\mathrm{Al}_{2} \mathrm{O}_{3}$ films in a Class 1000 cleanroom. The ALD reactor was evacuated to a base pressure of 3-5 mbar. Samples were allowed to equilibrate for $1 \mathrm{~h}$ before deposition began. The silver knives discussed in this study had ALD films applied at $100{ }^{\circ} \mathrm{C}$, while thermally evaporated silver thin film samples were deposited at $150{ }^{\circ} \mathrm{C}$. Trimethylaluminum and $\mathrm{H}_{2} \mathrm{O}$ were used as precursors to deposit $\mathrm{Al}_{2} \mathrm{O}_{3}$ with a deposition rate of $0.9 \AA$ /cycle, adjusting the number of cycles to produce the desired film thickness. $\mathrm{N}_{2}$ gas was used to purge the ALD sub-chamber of any by-products or remaining precursors between precursor pulses. During purge and pulse cycles, gases continuously flowed through the reactor sub-chamber. As shown in Fig. 2, the gases are introduced through the left side of the reactor and exit on the right. Precursor pulse and $\mathrm{N}_{2}$ gas purge times were adjusted from 0.5 to $2.0 \mathrm{~s}$, depending on the particular experiment, when depositing on 3D objects, to ensure gas delivery in the entire ALD chamber.

\section{Surface characterization}

The sterling silver knife was characterized after ALD film deposition using a Digital Instruments Dimension ${ }^{\text {TM }}$ 3100 atomic force microscope (AFM). Reported surface roughness values were calculated from the root mean square (RMS) of the surface profile. Five AFM scans in each area were obtained to calculate the RMS roughness and representative scans are reported.

Raman measurements of the sterling silver knife after ALD film application were obtained using a HORIBA Jobin-Yvon LabRAM ARAMIS Confocal Raman Microspectrometer. An excitation laser wavelength of $532 \mathrm{~nm}$ and a $1200 \mathrm{~L} / \mathrm{mm}$ grating were used for all measurements reported.

A scanning electron microscope (SEM) with energy dispersive spectroscopy (EDS) was used to characterize the surface of the silver knives after film deposition and ALD film removal. A Hitachi S-3400 Variable Pressure SEM was used with an accelerating voltage of $10-20 \mathrm{kV}$.

Surface composition of ALD film defects in the sterling silver knife was determined through $\mathrm{x}$-ray photoelectron spectroscopy (XPS) measurements using a Kratos Axis 65 X-ray Photoelectron Spectrometer, employing a monochromatic $\mathrm{Al}\left(\mathrm{K}_{\alpha}\right)$ source with a $125 \mathrm{~mm}$ Omnicron (EA 125) hemispherical analyzer with a seven-channel detection capability for photoemission analysis. The charge neutralizer was employed to prevent surface charging. All peaks were calibrated to the $\mathrm{C}$ s peak centered at $284.6 \mathrm{eV}$. XPS surface concentrations were calculated using CasaXPS $^{\mathrm{TM}}$ from the peak areas of $\mathrm{O} \mathrm{1s,} \mathrm{Ag} 3 \mathrm{~d}, \mathrm{Al} 2 \mathrm{p}, \mathrm{S} 2 \mathrm{p}$ and $\mathrm{C} 1 \mathrm{~s}$ using manufacturer supplied relative sensitivity factors.

\section{Electrochemical evaluation}

Electrochemical analysis was carried out on ALD coated thermally evaporated silver substrates using a threeelectrode cell with a $\mathrm{Ag} / \mathrm{AgCl}$ reference electrode and a 
platinum counter electrode. Before measurements, the Kapton $^{\mathrm{TM}}$ tape was removed from the corners of the silver sample. An area of $1.77 \mathrm{~cm}^{2}$ on the working electrode was created using a Neoprene ${ }^{\circledR}$ o-ring. A 1.0 molar $\mathrm{NaCl}$ (Sigma-Aldrich, reagent grade) solution made with ultrapure water (resistivity $>17 \mathrm{M} \Omega$ ) was de-aerated by bubbling $150 \mathrm{sccm} \mathrm{N}_{2}$ gas for $30 \mathrm{~min}$ prior to testing and 50 sccm $\mathrm{N}_{2}$ gas while measurements were taken. Electrochemical impedance spectroscopy (EIS) was performed immediately after the electrolyte was introduced to the electrode cell to determine the electrochemical response due to the pinholes, not the formation of tarnish. Measurements were performed in the frequency range of $10 \mathrm{mHz}-100 \mathrm{kHz}$ with a $5 \mathrm{mV}$ exciting signal amplitude, at open circuit potential (OCP).

\section{Porosity analysis}

ALD film porosity was evaluated from the EIS measurements by determining the fraction of uncoated silver in direct contact with the electrolyte. Film porosity $P_{R}$ was evaluated using Eq. (1) as the ratio of the polarization resistance of the uncoated $R_{p}^{o}(\Omega)$ and ALD coated samples $R_{p}(\Omega)$ [46].

$$
P_{R}=\frac{R_{p}^{o}}{R_{p}} \times 100 \%
$$

The polarization resistance was obtained from equivalent circuit modeling of the EIS measurements using ZView $^{\circledR}$ software. A simplified model, presented in Fig. 8 was used to reduce errors in the calculated polarization resistance where $R_{E}$ is the resistance of the electrolyte measured at the high frequency intercept, the charge transfer resistance $R_{C T}$ measured at the low frequency intercept, and the capacitance of the ALD film C $[28,30]$. The charge transfer resistance $R_{C T}$ is roughly equivalent to the polarization resistance $R_{p}$ [47], therefore the resistance at the low frequency intercept with the real axis was used to calculate the porosity of 5, 10, 20, 70, and $100 \mathrm{~nm}$ $\mathrm{Al}_{2} \mathrm{O}_{3} \mathrm{ALD}$ films in this study.

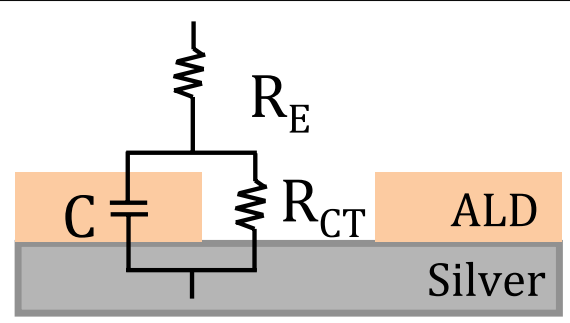

Fig. 8 Equivalent circuit model for EIS analysis: simplified equivalent circuit model for ALD coatings on silver used for fitting electrochemical impedance spectroscopy data, adapted from [29]

\section{Conclusions}

While ALD has previously been proven highly effective in protecting flat, 2-dimensional silver alloy surfaces from corrosion, coating non-ideal 3D objects can be more challenging. Limited flow of the ALD precursors around 3D objects and supports is an important factor. The precursor pulse and subsequent purge times must be increased to allow sufficient diffusion of precursors and by-products around complex surface topographies. Relatively thin ALD films offer insufficient corrosion protection on art objects, where existing local surface oxides and/or surface pre-treatment residues may cause pinhole defects. Thicker ALD films are found to suppress pinhole defects that may be present during the initial film growth. The $\mathrm{Al}_{2} \mathrm{O}_{3}$ ALD coatings can be effectively removed from the silver surface by dissolving the coating in $0.5 \mathrm{wt} \%$ (aq.) $\mathrm{NaOH}$. Our results demonstrate that relatively thick ALD films, deposited with sufficiently long precursor pulse and purge times, may be effective in protecting non-mixed media silver and silver alloy cultural heritage objects.

\section{Authors' contributions}

AM carried out the experiments and analysis described here, and contributed to writing and revisions of the article; EB, TW and GG contributed to the experimental design and interpretation and writing and revisions of the article, RP contributed to the experimental design, interpretation, the writing and revisions of the article and the direction of the project. All authors read and approved the final manuscript.

\section{Author details}

${ }_{1}^{1}$ Department of Materials Science and Engineering, University of Maryland, College Park, MD 20742, USA. ${ }^{2}$ E-squared Art Conservation Science, Washington, DC 20001, USA. ${ }^{3}$ The Walters Art Museum, 600 N. Charles Street, Baltimore, MD 21201, USA

\section{Acknowledgements}

This work was supported by the National Science Foundation under SCIART grants DMR 1041809 and DMR 1041803. The authors would also like to thank Professor Eric Wachsman and Professor Liangbing Hu and their respective group members for access to EIS equipment used for this analysis.

\section{Competing interests}

The authors declare they have no competing interests connected with the information contained in this manuscript.

Received: 1 July 2015 Accepted: 10 November 2015

Published online: 01 December 2015

\section{References}

1. Graedel T. Corrosion mechanisms for silver exposed to the atmosphere. J Electrochem Soc. 1992;139:1963-70.

2. Bennett $H$, Peck R, Burge D, Bennett J. Formation and growth of tarnish on evaporated silver films. J Appl Phys. 1969;40:8.

3. Rice D, Peterson P, Rigby E, Phipps P, Cappell R, Tremoureux R Atmospheric corrosion of copper and silver. J Electrochem Soc. 1981;128:275-84.

4. Hallett K, Thickett D, McPhail D, Chater R. Application of SIMS to silver tarnish at the British Museum. Appl Surf Sci. 2003;203-204:789-92.

5. Baše T, Bastl Z, Havránek V, Lang K, Bould, J, Londesborough M, Macháček J, Plešek J. Carborane-thiol-silver interactions. A comparative study of the molecular protection of silver surfaces. Surf Coat Tech. 2010;204, 2639-46. 
6. Stevens D. The effects of fingerprints on silver. V\&A Conserv J. 2011;59:13.

7. Museums, Libraries and Archives Design Parameters. In: ASHRAE Handbook: heating, ventilating, and air-conditioning applications, SI Edition, vol. 21. ASHRAE: Atlanta; 2003. pp. 1-21.

8. Luxford N, Thickett D. Preventing silver tarnish—lifetime determination of cellulose nitrate lacquer. In: Metal 07, Interim Meeting of the ICOM-CC Metal Working Group; 2007. pp. 88-93.

9. Reedy C, Corbett R, Long D, Tatnall R, Krantz B. Evaluation of three protective coatings for indoor silver artifacts. Objects Specialty Group Postprints Am Inst Conserv. 1999;6:41-69.

10. Metcalf S. Weighing up silver objects: evaluating past and future conservation methods. Vic Albert Mus Conserv J. 1997;22:4-5.

11. Costa V. The deterioration of silver alloys and some aspects of their conservation. Rev Conserv. 2001;2:18-34.

12. Grisson C, Grabow N, Smith Riley C, Charola A. Evaluation of coating performance on silver exposed to hydrogen sulfide. J Am Inst Conserv. 2013;52:82-96.

13. Sease L, Selwyn L, Zubiate S, Bowers D, Atkins D. Problems with coated silver whisker formation and possible filiform corrosion. Stud Conserv. 1997:42:1-10

14. Thickett $D$, Hockey $M$. The effects of conservation treatments on the subsequent tarnishing of silver. Conserv Methods. 2002;155-61.

15. Selwitz C. Cellulose nitrate in conservation. In: Volume 2 of Getty Conservation Institute Research in conservation. Getty Publications; 1988. pp. 38-40.

16. Paussa L, Guzman L, Marin E, Isomaki N, Redrizzi L. Protection of silver surfaces against tarnishing by means of alumina/titania-nanolayers. Surf Coat Technol. 2011;206:976-80.

17. Breitung E, Marquardt A, Gates G, Weisser T, Henn-Lecordier L, Rubloff G, Phaneuf R. Atomic layer deposition films as protective coatings for silver In: American Insitute of Conservation, Research and Technical Studies Proceedings, 40th Annual Meeting, vol. 3; 2010

18. Marquardt A, Breitung E, Weisser T, Gates G, Rubloff G, Phaneuf R. Characterization of atomic layer deposited films as diffusion barriers for art objects. Electrochem Soc Trans. 2013;58:277-86.

19. Leskela M, Ritala M. Atomic layer deposition (ALD): from precursors to thin film structures. Thin Solid Films. 2002;409:138-46.

20. Niinistö L, Päiväsaari J, Niinistö J, Putkonen M, Nieminen M. Advanced electronic and optoelectronic materials by atomic layer deposition: an overview with special emphasis on recent progress in processing of high-k dielectrics and other oxide materials. Phys Status Solidi A. 2004;201:1443-52.

21. Puurunen R. Surface chemistry of atomic layer deposition: a case study for the trimethylaluminum/water process. J Appl Phys. 2005;97:52.

22. Sneh O, Clark-Phelps R, Londergan A, Winkler J, Seidel T. Thin film atomic layer deposition equipment for semiconductor processing. Thin Solid Films. 2002;402:248-61.

23. Perez I, Robertson E, Banerjee P, Henn-Lecordier L, Son S, Lee S, Rubloff G. TEM-based metrology for $\mathrm{HfO}_{2}$ layers and nanotubes formed in anodic aluminum oxide nanopore structures. Small. 2008;4:1223.

24. Banerjee P, Perez I, Henn-Lecordier L, Lee S, Rubloff G. Nanotubular metalinsulator-metal capacitor arrays for energy storage. Nat Nanotechnol. 2009;4:292.

25. Matero R, Ritala M, Leskelä M, Salo T, Aromaa J, Forsén O. Atomic layer deposited thin films for corrosion protection. J Phys IV. 1999;9:493-9.

26. Carcia P, McLean R, Sauer B, Reilly M. Atomic layer deposition ultra-barriers for electronic applications - strategies and implementation. J Nanosci Nanotechnol. 2011;11:7994-8.

27. Abdulagatov A, Yan Y, Cooper J, Zhang Y, Gibbs Z, Cavanagh A, Yang $\mathrm{R}$, Lee $\mathrm{Y}$, George $\mathrm{S}$. $\mathrm{Al}_{2} \mathrm{O}_{3}$ and $\mathrm{TiO}_{2}$ atomic layer deposition on copper for water corrosion resistance. Am Chem Soc Appl Mater Interfaces. 2011;3:2493-4601.

28. Díaz B, Światowska J, Maurice V, Seyeux A, Normand B, Härkönen E, Ritala M, Marcus P. Electrochemical and time-of-flight secondary ion mass spectrometry analysis of ultra-thin metal oxide $\left(\mathrm{Al}_{2} \mathrm{O}_{3}\right.$ and $\left.\mathrm{Ta}_{2} \mathrm{O}_{5}\right)$ coatings deposited by atomic layer deposition on stainless steel. Electrochim Acta. 2011;56:10516-23.

29. Díaz B, Härkönen E, Światowska J, Maurice V, Seyeux A, Marcus P, Ritala M. Low-temperature atomic layer deposition of $\mathrm{Al}_{2} \mathrm{O}_{3}$ thin coatings for corrosion protection of steel: surface and electrochemical analysis. Corros Sci. 2011;53:2168-75.

30. Groner M, Fabreguette F, Elam J, George S. Low-temperature $\mathrm{Al}_{2} \mathrm{O}_{3}$ atomic layer deposition. Chem Mater. 2004;16:639-45.

31. Quinchon J, Tranchant J. Nitrocellulses: the materials and their applications in propellants, explosives and other industries. New York: Wiley; 1989.

32. Yang C, Shen W, Zhang Y, Ye Z, Zhang X, Li K, Fang X, Liu X. Colortuning method by filling porous alumina membrane using atomic layer deposition based on metal-dielectric-metal structure. Appl Opt. 2014;53:A142-7.

33. Guo S, Sushkov A, Park D, Drew H, Kolb P, Herman W, Phaneuf R. Impact of interface roughness on the performance of broadband blackbody absorber based on dielectric-metal film multilayers. Opt Express. 2014;22:1952-62.

34. Park D, Lee C, Herman W. Analysis of multiple reflection effects in reflective measurements of electro-optic coefficients of poled polymers in multilayer structures. Opt Express. 2006;14:8866.

35. Levy D, Freeman D, Nelson S, Cowdery-Corvan P, Irving L. Stable ZnO thin film transistors by fast open air atomic layer deposition. Appl Phys Lett. 2008;92:192101.

36. Jur J, Parsons $\mathrm{G}$. Atomic layer deposition of $\mathrm{Al}_{2} \mathrm{O}_{3}$ and $\mathrm{ZnO}$ at atmospheric pressure in a flow tube reactor. ACS Appl Mater Inter. 2011;3:299-308.

37. Airaksinen S, Bañares M, Krause A. In situ characterization of carbon-containing species formed on chromia/alumina during propane dehydrogenation. J Catal. 2005;230:507-13.

38. Zeng Z, Natesan K. Relationship of carbon crystallization to the metaldusting mechanism of nickel. Chem Mater. 2003;15:872-8.

39. Li Q, Sui Z, Zhou X, Shu Y, Zhou J, Chen D. Coke formation of Pt-Sn/Al $\mathrm{O}_{3}$ catalyst in propane dehydrogenation: coke characterization and kinetic study. Top Catal. 2011;54:888-96.

40. Tuinstra F, Koenig J. Raman spectrum of graphite. J Chem Phys. 1970;53:1126.

41. Yanguas-Gil A, Elam J. Simple model for atomic layer deposition precursor reaction and transport in a viscous-flow tubular reactor. J Vac Sci Technol A. 2012;30:01A159.

42. Yanguas-Gil A, Elam J. A Markov chain approach to simulate atomic layer deposition chemistry and transport inside nanostructured substrates. Theor Chem Acc. 2014;133:1465.

43. Dendooven J, Devloo-Casier K, Ide M, Grandfield K, Kurttepeli M, Ludwig K, Bals S, Van Der Voort P, Detavernier C. Atomic layer deposition-based tuning of the pore size in mesoporous thin films studied by in situ grazing incidence small angle X-ray scattering. Nanoscale. 2014;6:14991.

44. Zhang Y, Bertrand J, Yang R, George S, Lee Y. Electroplating to visualize defects in Al2O3 thin films grown using atomic layer deposition. Thin Solid Films. 2009;517:3269-72.

45. Zhang Y, Seghete D, Abdulagatov A, Gibbs Z, Cavanagh A, Yang R, George $\mathrm{S}$, Lee $\mathrm{Y}$. Investigation of the defect density in ultra-thin Al2O3 films grown using atomic layer deposition. Surf Coat Technol. 2011;205:3334-9.

46. Tato W, Landolt D. Electrochemical determination of the porosity of single and duplex PVD coatings of titanium and titanium nitride on brass. J Electrochem Soc. 1998;145:4173-81.

47. Andrade C, Bolzoni F, Cabeza M, Nóvoa X, Pérez M. Measurement of steel corrosion in concrete by electrochemical techniques: Influence of the redox processes in oxide scales. In: Bonora P, Deflorian F, editors. Electrochemical approach to selected corrosion and corrosion control studies: (EFC 28). Maney Publishing; 2000. pp. 332-43. 